materials for transporting the MISS/LIBRA system are available from James Cleary, Sociology Data Center, Department of Sociology, University of Minnesota, Minneapolis, Minnesota 55455.

\section{REFERENCES}

Anderson, R. E. A survey of application software for social data analysis instruction. Proceedings of a Conference on Computers in the Undergraduate Curricula, Dartmouth College, Hanover, New Hampshire, 1971. Pp. 135-141.

Anderson, R. E., \& Coover, E. R. Wrapping up the package: Critical thoughts on applications software for social data analysis. Computers and the Humanities, 1972, 7, 81-95.

Anderson, R. E., \& Gross, J. Mini-computers in a social science instructional context. Proceedings of the ACM Conference, 1972.

Cleary, J. D. MISS primer. Minneapolis, Minn: Sociology Data
Center, Department of Sociology, University of Minnesota, 1973.

Cline, H. H., \& Meyers, D. Problem-solving computer systems for instruction in sociology. American Sociologist, 1970, 5, 265-270.

\section{NOTES}

1.John Vincent is presently an Assistant Professor of Sociology at the University of Minnesota and is an instructor in the statistics/methods sequence,

2. Due to space limitations, extensive labeling of output is not available on MISS. This limitation is minimized, however, by supplying or constructing code books for the data sets.

3. This limitation on the size of the raw data matrix does not apply to files residing on disk storage. In other words, a large data file might be stored on the disk, but only 700 elements from that file could be analyzed at any one time.

4. In a hardware configuration offering more disk storage area than our hardware system permits, these space limitations of MISS could easily be lifted.

Behavior Research Methods \& Instrumentation

1974, Vol. 6, No. 2, 200-204

\title{
OMNI-SHRIMP: An interpretive language which mimics OMNITAB*
}

\author{
G. SCOTT HARRIS, JAMES M. SWANSON, and JOANNE L. DUERR \\ University of Texas, Austin, Texas 78712
}

\begin{abstract}
A description of OMNITAB, an interpretive language, is provided along with a discussion of its use. The major attributes of SHRIMP (ah interactive mathematical package developed at the University of Texas) are pointed out in detail and its use and relationship to OMNITAB defined. An example is included to show SHRIMP compatibility with OMNITAB.
\end{abstract}

OMNITAB is an interpretive language developed by the National Bureau of Standards for use in statistical and mathematical problems in research. The OMNITAB language is easy to learn because it resembles English, and only a small portion of the language is necessary for the beginner.

Two successful applications of OMNITAB in the classroom have been described in the literature. A paper by Swanson, Harris, and Ledlow (1973) gives a description of an application for teaching undergraduate statistics to students completely unfamiliar with both statistical concepts and the computer. Furthermore, Swanson, Riederer, and Weekly (1973) describe an application in a graduate course for teaching matrix methods in applied statistics.

\section{HISTORICAL BACKGROUND}

The University of Texas has a long-standing involvement in academic computing. This involvement led to the development of a large academic Computation Center, independent of administrative computing, comprised of a Control Data 6400 and a Control Data 6600 together with Texas's own dual operating system. Appended to this are two high-speed remote terminals, 15 medium-speed remote terminals, and 64 Teletype

* Reprints may be obtained from G. Scott Harris, Computation Center, University of Texas, Austin, Texas 78712 . lines, soon to be doubled.

There is a good reason for mentioning these figures. They indicate a growing trend in a university such as Texas (with 40,000 students) to make available a new form of computing: time-shared interactive instruction. The OMNITAB and SHRIMP systems illustrate the use of facilities such as these in a new way.

Previously, academic computing has been heavily weighted toward numerical methods in mathematics and the physical sciences. In recent years, however, academic computing has been developing interactive tutorial systems, such as CLIC at Texas, for student drill work. Now there is another use of the computer which lies between the page-flipping drill sessions and the mastery of a complex computer language.

An example of this kind of application is the OMNITAB system. Originally used for research when developed by the National Bureau of Standards, it has a number of features which fill this gap. First, it resembles English and is easy for the beginner to master with the positive feedback of early success. Second, it is a true procedural language, placing the power of the computer under the user's control (see Hogben, Peavy, \& Varner, 1971). Third, when using the modifications of the University of Texas, a user receives immediate feedback on his every directive and even on instructions given by a professor (see Harris, 1971).

These features have made OMNITAB extremely 


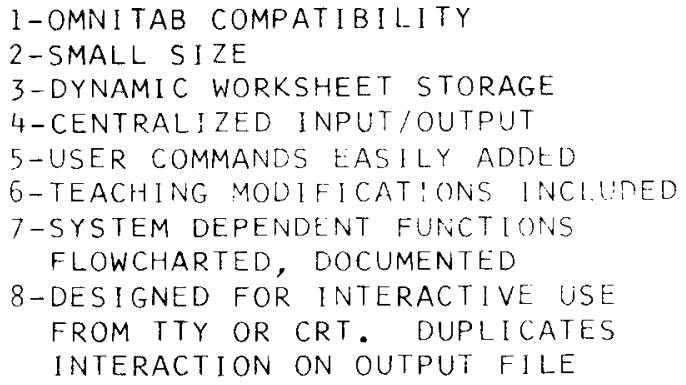

Fig. 1. SHRIMP features.

popular at Texas. So popular, in fact, that we must replace it for interactive teaching use! Briefly, this turn of events proceeded as follows: OMNITAB was procured from the National Bureau of Standards and installed at Texas. It was then modified to be interactive, with a smaller worksheet. Its use went from 0 to 1000 jobs per month in the first year. Then it was modified further as a teaching tool in work sponsored by the Project C-BE (Computer-Based Education) to allow OMNITAB to be externally initialized, such as by an instructor, and to facilitate certain printing formats on Teletype. As a result, OMNITAB is also now in use for teaching 1200 business' students, 200 psychology students, and many others in library sciences and similar areas. James Swanson has developed a set of 20 laboratories using OMNITAB for self-paced instruction in statistics.

All of this means that the number of OMNITAB users on our system has grown quite large, placing a load on our system because of the size of OMNITAB. We have made most of the modifications which can be made easily to convert OMNITAB into a teaching tool, and yet it is still large. Several copies at once in our machine is a load. This is something we already knew, of course. For, in spite of the fact that approximately 50 universities now run OMNITAB, we have had many requests for information from places that simply could not run so large a program.

The University of Texas is not only committed to its own immediate needs, of course, but is also concerned with transporting and sharing solutions to computing problems with other sites. As a member of the CONDUIT network, the University of Texas intends that the system will not only solve our own problem but be transportable to solve the same problem at other sites. CONDUIT consists of the computers of Oregon State, North Carolina, Dartmouth, and the Universities of Iowa and Texas. CONDUIT serves a consortium of 100 schools and 275,000 students. It can do this because each member school of CONDUIT is also involved in a local network, as Texas is in the Southwest with over 22 other schools. The SHRIMP system will be available through the CONDUIT Coordinator at the University of Texas.

\section{SHRIMP FEATURES}

SHRIMP is an interactive mathematical package

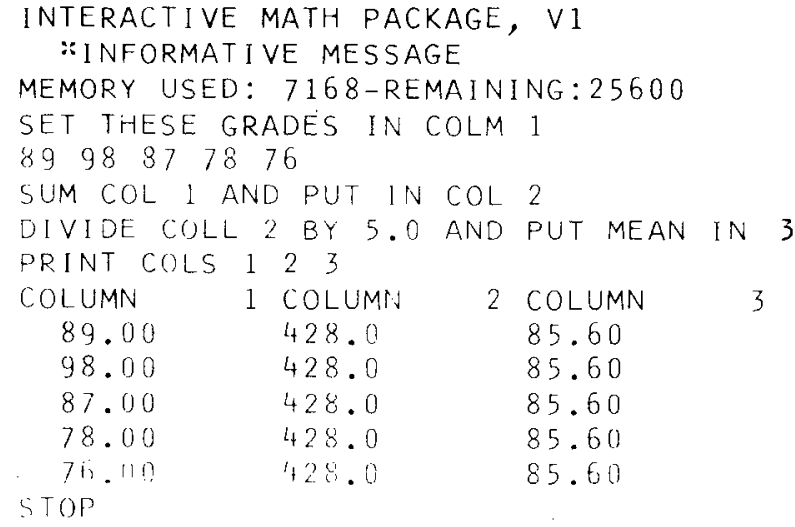

Fig. 2. A simple SHRIMP program.

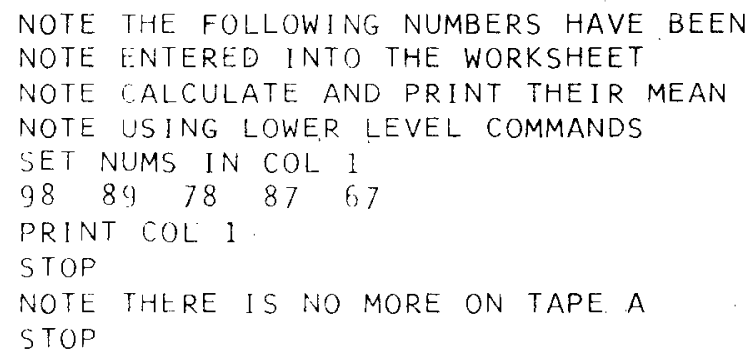

Fig. 3. A simple instructor file.

HELLO. THE SHRIMP SYSTEM IS BEING PREPARED FOR YOUR USE. AFTER YOU HEAR A BELL, TYPE READ TAPE A

AND YOU WILL RECEIVE SOME INSTRUCTIONS. (THE BELL INDICATES WHEN THE SYSTEM IS READY TO ACCEPT YOUR TYPING.)

Fig. 4. Beginning instructions.

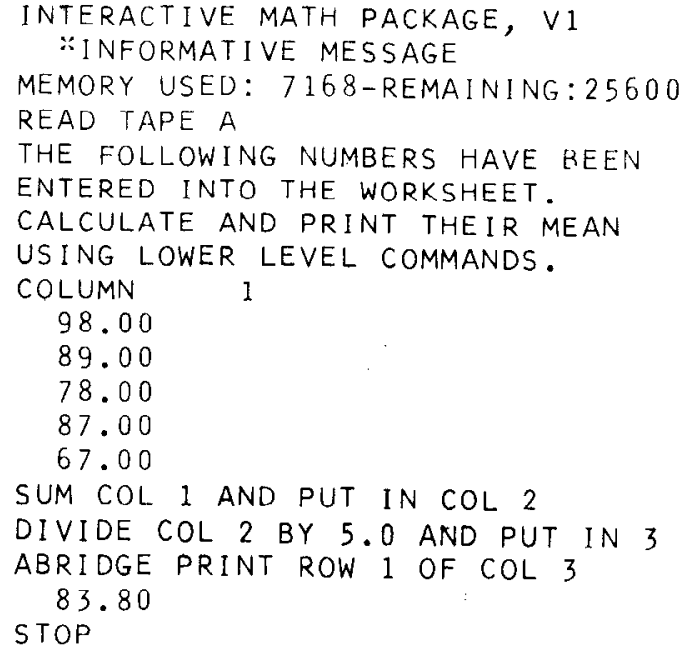

Fig. 5. A simple SHRIMP program using an instructor file.

developed at the University of Texas (see Fig. 1). It is intended to be as easy to use and as powerful as OMNITAB and yet to be efficient enough in terms of size and other factors to be competitive in a time-sharing 
environment. Furthermore, SHRIMP is intended to be transportable. These goals are not achieved at the expense of optimum performance, however, but rather by functionalizing and centralizing access to certain machine-dependent features which are available at most sites.

The major attributes of SHRIMP are as follows: (1) A subset of OMNITAB may be executed on SHRIMP. Thus, a student not only learns to use the computer, he also acquires a valuable research tool useful later at approximately 50 universities. (2) SHRIMP is small. Using overlays, it currently executes in 7000 (decimal) words of memory on a CDC 6600 . (3) The worksheet storage is variable, allowing optimum use of memory. (4) All input and output is in a centralized routine, allowing easy local adaptation. (5) User commands may be easily added. A local site may write a new command without detailed knowledge of SHRIMP structure and input/output. (6) The teaching modifications made at Texas are included in SHRIMP. (7) System dependent functions (one necessary, two optional) have flow charts provided for easy local implementation. (8) SHRIMP output is designed for Teletype use. A duplicate of all that transpires on the Teletype or CRT is produced on the output file for the student's and instructor's later use.

\section{A SIMPLE SHRIMP PROGRAM}

The SHRIMP language resembles simple English sentences, beginning with verbs, directing the manipulation of a worksheet inside the computer of rows and columns (see Fig. 2). The figure illustrates one such trivial program. (Note that all examples in this paper are kept trivial for the sake of clarity, but many powerful higher level features are to be found in SHRIMP, just as in OMNITAB.) A SHRIMP command occurs on a single line. Only the first word and the numbers matter in general, the other words being the user's mnemonics. Literal number values are indicated by the use of the decimal point, other values being interpreted as column numbers or row numbers or some other quantity appropriate to the command.

\section{AN INSTRUCTOR FILE}

The teaching modifications made to OMNITAB are also in SHRIMP (see Fig. 3). This file was previously constructed by an instructor and placed on an auxiliary file (in this case named " $A$ "). It consists of instructions to the student and data for him to analyze. The command "READ TAPE A" on the part of the student transfers control to this file. The command "STOP" on

INTERACTIVE MATH PACKAGE, VI :INFORMATIVE MESSAGE

MEMORY USED: 7168-REMAINING: 25600

READ TAPE A

OMNILAB O-- AN INTRODUCTION TO THE OMNITAB LANGUAGE

THE OMNITAB LANGUAGE ALLOWS YOU TO USE SIMPLE ENGLISH

SENTENCES TO PROGRAM A COMPUTER. THIS LAB EXERCISE WILL SHOW YOU HOW TO USE OMNITAB INSTEAD OF A DESK CALCULATOR OR PAPER AND PENCIL TO PERFORM THE NUMERICAL CALCULATIONS WHICH YOU ENCOUNTER IN A STATISTICS CLASS.

OMNITAB OPERATES ON A EWORKSHEET $=$ PRINCIPLE. THE WORKSHEET IS USED JUST AS A SHEET OF PAPER TO HOLD NUMBERS

THE OMNITAB WORKSHEET

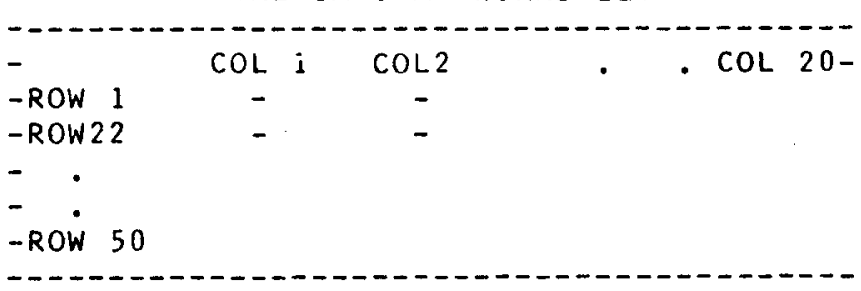

INSTEAD OF WRITING NUMBERS DOWN IN A COLUMN ON A SHEET OF PAPER, THE COMMAND SET IS USED TO PUT DATA INTO THE WORKSHEET.

FOR EXAMPLE: SET THE FOLLOWING NUMBERS INTO COL 1

$\begin{array}{llllll}123.45 & 118.92101 & 101.0 & 139.947 & 109.666667\end{array}$

WOULD PUT FIVE NUMBERS INTO COL 1 OF THE WORKSHEET.

(NOTE THAT THE DATA (NUMBERS) ARE SEPARATED BY SPACES.) 
Fig. 6. A complete teaching laboratory session as used in OMNITAB and SHRIMP.

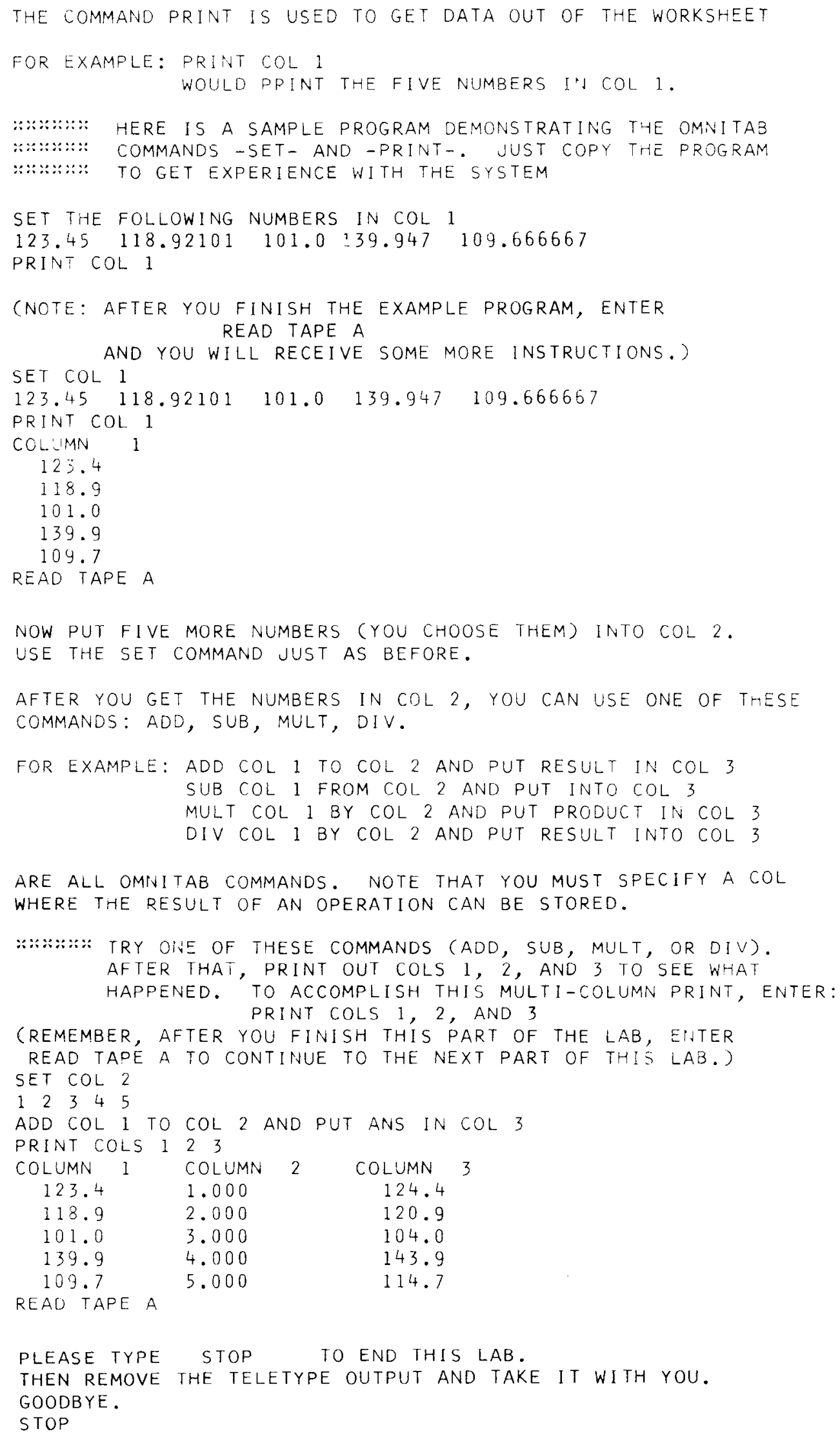


this file does not totally stop SHRIMP, but rather transfers control back to the student.

\section{BEGINNING INSTRUCTIONS}

When executing SHRIMP in the student lab mode, these instructions are printed to the student as he begins (see Fig. 4).

\section{A SIMPLE SHRIMP PROGRAM USING THE INSTRUCTOR FILE}

Using SHRIMP and the previous instructor file, we have performed this trivial laboratory (see Fig. 5). Note that we transferred control of SHRIMP to Tape A using the "READ TAPE A" command, received instructions, and control was returned to us.

\section{AN OMNITAB LABORATORY (OMNILAB) PERFORMED WITH SHRIMP}

This example is included to show SHRIMP compatibility with OMNITAB and to acquaint you with further features of the teaching facilities and the OMNITAB language (see Fig. 6).

\section{SHRIMP DYNAMIC WORKSHEET}

If your computer can grant changes in memory size to a running program, SHRIMP can optimize its size through the dimension command (see Fig. 7). Note that when the product of rows and columns necessitates a change in size SHRIMP issues a message indicating current memory consumption.

\section{SHRIMP COMMAND ADDING PROCEDURE}

SHRIMP has functions which take care of all input/output, parsing of commands, and worksheet access (see Fig. 8). The user may write a new command using the arguments placed in common by the parser and access the worksheet through the cell function, which can store or retrieve any particular row and column. The command goes in a simple data table.

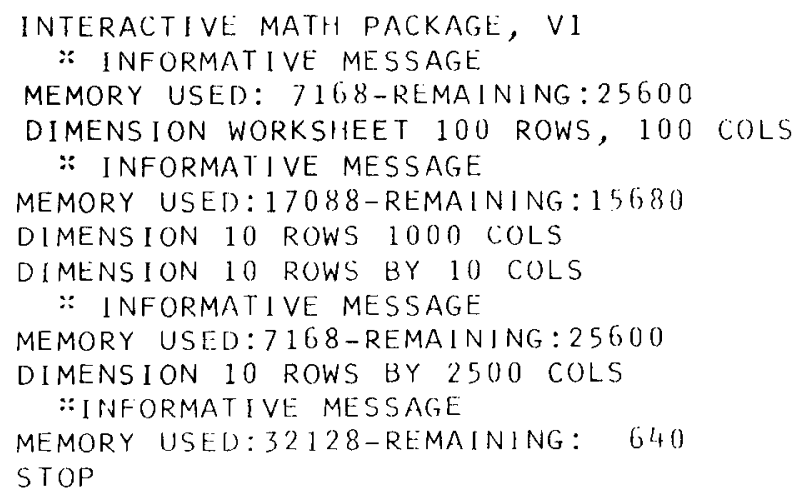

Fig. 7. SHRIMP dynamic worksheet feature.

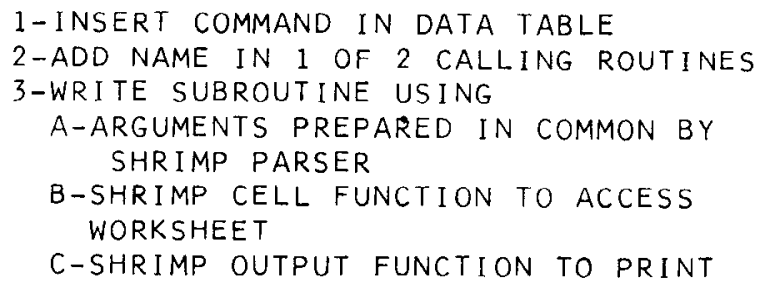

Fig. 8. SHRIMP command adding procedure.

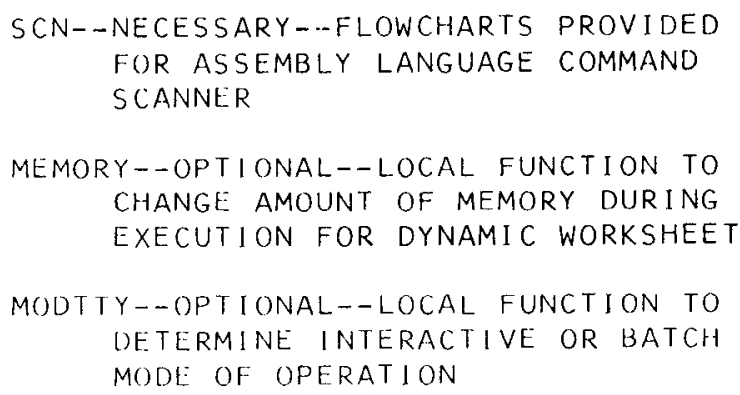

Fig. 9. SHRIMP system dependent functions.

\section{SYSTEM DEPENDENT FUNCTIONS}

SHRIMP's transportability comes not through clumsy code, but through documentation and centralization of system dependent functions (see Fig. 9). Complete flow charts are provided for the necessary command scanner. The optional dynamic worksheet storage requires a function to obtain and release memory. And the optional batch mode requires a function which indicates an interactive terminal situation. The latter two options may be locked out of SHRIMP by setting a variable in common.

\section{CONCLUSION}

The SHRIMP system offers an exciting possibility in computer access. Response to its inception and requests for copies are already coming in. The combination of easy learning and procedural power open many alternative uses. We at Texas welcome your suggestions for commands and applications. Once again, requests for SHRIMP information should be directed to George Culp, CONDUIT Curriculum Coordinator, Computation Center, University of Texas, Austin, Texas 78712.

\section{REFERENCES}

Harris, G. S. UT OMNITAB II, Version 5.0: User's reference manual supplement. Austin, Tex: University of Texas Computation Center, TPB-132, 1971 (amended)

Hogben, D., Peavy, S., \& Varner, R. OMNITAB II: User's reference manual. (National Bureau of Standards Technical Note 552.) Washington, D.C: U.S. Government Printing Office, 1971.

Swanson, J., Harris, S., \& Ledlow, A. Using OMNITAB interactively in a statistics laboratory. Behavior Research Methods \& Instrumentation, 1973, 5, 199-204.

Swanson, J., Riederer, S., \& Weekly, H. Using OMNITAB to teach applied statistics. Computers in the Undergraduate Curriculum, 1973, 4, 128-134. 